\title{
PLANTEAMIENTOS TEÓRICOS SOBRE LA 'INGURGITACIÓN EMOCIONAL’ APLICADA A LA COREOGRAFÍA DE DANZA CONTEMPORÁNEMA
}

\section{Manuel Garzón Albarrán}

Investigador independiente

\section{Resumen}

El presente artículo pretende rescatar el concepto de 'ingurgitación emocional' planteado por por Jean-Marie Pradier (2001) como fenómeno emocional inserto en la matriz de la obra de danza contemporánea. Con el estudio histórico sobre la trayectoria coreológica se localiza el nacimiento del fenómeno, aplicado a las artes escénicas, en las vanguardias modernistas y su planteamiento de restructuración de lo escénico. Se analizará cómo la situación social de inicios del siglo XX provoca una cristalización del hombre en la escena, mostrando su psique y sus emociones, encarnadas en una coreografía que invita a revivir 'las pasiones' dirigidas hacia 'los miedos', planteando una etnoescenología concreta. Mediante el estudio de obras significativas del momento se plantea cómo la 'ingurgitación emocional' vive en los procesos creativos de un modo activo y consciente.

Palabras clave: INGURGITACIÓN EMOCIONAL; COREOGRAFÍA; SEMIÓTICA ESCÉNICA; ETNOESCENOLOGÍA; DANZA CONTEMPORÁNEA

\section{THEORETICAL APPROACHES ON THE 'EMOTIONAL ENGORGEMENT’' APPLIED TO THE CONTEMPORARY DANCE'S CHOREOGRAPHY}

\section{Abstract}

This article maintains the premise to give an answer about the concept of 'emotional engorgement' raised by Jean-Marie Pradier (2001) as an emotional phenomenon of structure contemporary dance work. With the historical study of the choreology trajectory, the beginnings of the phenomenon is located, applied to the performing arts, in the modernist avant-gardes and their suggestions about restructuring the scenic are raised. It will be analyzed how the social situation of the early twentieth century causes a crystallization of man on the scene, showing his psyche and his emotions, embodied in a choreography that invites to revive 'passions' directed towards 'fears', proposing a specific ethnoscenology. Through the study of significant works of the moment it is considered how 'emotional engorgement' lives in the creative processes in an active and conscious way.

Key words: EMOTIONAL ENGORGEMENT; CHOREOGRAPHY; STAGE SEMIOTICS; ESTHNOSCEMOLOGY; CONTEMPORANY DANCE

\footnotetext{
Garzón Albarrán. Manuel. 2021. 'Planteamientos teóricos sobre la "ingurgitación emocional' aplicada a la coreografía de danza conteporánema'. AusArt 9 (1): 185-195. DOI: 10.1387/ausart.22546
}

\section{AUSART}




\section{REPLANTEAMIENTO DE LAS EMOCIONES EN LA NUEVA ESCENA}

El rumbo histórico de la coreología centrado en la producción de obras de danza clásica, sufrió modificaciones, desde los inicios del pasado siglo, al trazar bifurcaciones en su praxis creativa, que provocó el planteamiento y estructura de nuevos estilos de danza: contemporánea y neoclásica (Sánchez Bueno 2011), cuyo estudio se afrontará atendiendo a sus plataformas teórica y práctica, llegando a insertarse dentro de la Académica y la Universidad (Mera 2011; Collazo Albizu 2015), siguiendo los patrones de la danza clásica. La danza contemporánea y su hermana danza neoclásica, surgen paulatinamente desde las vanguardias europeas desarrollándose mediante una prolífica producción de creadores y obras que, como descendencia de la danza moderna, buscan despertar al espectador invitando a la experimentación y la reflexión tras el disfrute visual (Goldberg 1988; Taylor 2011; Sánchez 1999)1.

En un comienzo, esta vida escénica surge bajo la necesidad de la creación práctica (Sánchez Bueno 2011), evocada por unos deseos de renovación y reestructuración de artistas con ansias de mejoras y de evolución hacia la 'vida moderna' (Sánchez 1999). Una actividad creativa compuesta por mensajes y actos comunicativos que plantearon un estrechamiento en la relación entre obra y espectador (Bürger 1974)².

Para los expresionistas, las pautas coreográficas con las que se estructuraba la obra de ballet eran arcaicas, anticuadas y poco populistas (Goldberg 1988), necesitando la presencia de nuevas herramientas estructurales, que hablasen de los agentes y sus interacciones, de la sociedad y de la forma real de vivir el contexto de entreguerras. Para poner en marcha aquellos deseos se pautaron nuevos parámetros que plantearon un abordaje profundo en la reconstrucción la obra escénica. Entre las acciones realizadas: se modificó el valor del cuerpo en la escena, añadiendo nuevos recursos de movimiento al vocabulario dancístico, ampliando el trabajo kinesférico (Laban 1950) y la proyección gestual (Andrew 2014) ${ }^{3}$. Asimismo, se sustituye la dramaturgia y los libretos ideales por temas reales y conceptos relacionados con los interrogantes existencialistas, como la muerte, la locura, la enfermedad, etc. Todos estos elementos permitían realizar cierto juego temporal de la escena, pudiendo fracturar el 'continuum temporal' y dando paso a la estructura de puzle, una construcción de la obra compuesta por varios segmentos coreográficos, ubicados en diferentes contextos, que hablan de un mismo concepto, planteado como objetivo general de la obra. 
Estas innovaciones pudieron instalarse en la danza tras haberse realizado la 'apertura' de la obra escénica, definida como concepto del 'giro corporal' por Grumann Sölter (2008) y apoyado por Sánchez (1999) con su teoría de 'reteatralización del teatro'. La tesis de estos autores recoge las modificaciones estructurales de la obra modernista, cuyas réplicas se encuentran en las manifestaciones escénicas ubicadas en el umbral entre teatro y danza, que dieron vida al perfomance art, junto a múltiples lineas artísticas como happening, body-art, fluxus, 'arte conceptual' y demás senderos performativos (Goldberg 1988), que juegan con la comunicación teatral y danzada, desarrollándose con prolijio a partir de la década de los cincuenta hasta la actualidad (Grumann Sölter 2008).

Del mismo modo, con el 'giro corporal' se gestaron nuevas corrientes artísticas incluidas también en la pintura y la imagen, como el Surrealismo, Futurismo y el movimiento Dadá, cuyo trabajo se efectúa sobre la premisa de conseguir la 'libertad' y 'verdad' del hombre reflejado en el Arte (Gómez García 2001). Dicha 'libertad' está aplicada en la exposición del discurso, situaciones sociales y los sentimientos íntimos, en busca de una cristalización del agente que fracture las máscaras de las normas sociales, y, de este modo, se acerque más a la 'verdad' del agente social (Sánchez 1999).

Para ello, cada estilo asumió elementos transgresores como la sátira, el sarcasmo, la ironía, para construir sus obras, sin olvidar la practica 'lo absurdo' aplicado como símbolo del rechazo de la dura realidad social del momento. Además, se realizó un 'giro corporal' en la estética de la obra, afectando lo visual y lo sonoro mediante la utilización de melodías atonales y sonidos urbanos, envueltos con diseños de vestuario que rompen la línea tradicional (realista) insertando en el cuerpo volúmenes artificiales y geometría (abstracción) ${ }^{4}$.

Todas esas obras se encontraron unidas por los deseos y ambiciones de creadores que hablaban de sí mismos, de los seres que los rodean y del colectivo social, poniendo en práctica la etnoescenología (Pradier 1997; Sapiain 2015). Este neologismo, propuesto por Pradier, fue definido por el mismo autor como disciplina que pretende "contribuir a un mejor conocimiento de la naturaleza del hombre a partir del examen de las estrategias cognitivas, de las técnicas corporales y mentales que implican la emergencia de acontecimientos cuya dimensión espectacular los torna relevantes para la comunidad" $(1997,52)$. Como método ${ }^{5}$ se realiza "el estudio, en las diferentes culturas, de las prácticas y de los comportamientos humanos espectaculares organizados" (Pavis 1983 , 191). Por tanto, podemos entender que, como disciplina, centra en el 
acto corporal aquellos aspectos imaginarios procedentes de lo social, escenificados mediante lo teatral, en definitiva, un cóctel de elementos para exponer lo íntimo, mente y alma en el discurso escénico.

\section{FENÓMENO EMOCIONAL HACIA EL VACÍO}

La belleza plástica con la que se trataba la obra de ballet, anterior al s. XX, era completamente inviolable. Se valoraba lo positivo, la exaltación de la belleza y el mundo onírico como plataforma paralela a la realidad (Markessinis 1995). La emoción se exponía como elemento esencial de los actos y las vidas apasionadas de los personajes, otorgando gran importancia a la catarsis, al igual que la cultura en general (Sorley 1972). Sin embargo, el 'giro corporal' afectó de manera proporcional a esta exhibición de 'vida perfecta', que poco tenía que ver con la realidad (Viana 2009) ${ }^{6}$. Los artistas comenzaron a plantear las pasiones humanas sin tabús, mostrando el dolor, la ira, el desgarro, la locura y la pérdida con la dureza de todos los caracteres, provocando una catarsis invertida, dirigida hacia un estado de vacío emocional causado por el colapso de múltiples emociones que impactan en el espectador, provocando así un nuevo despertar emocional (Pradier 2001).

El término 'ingurgitación emocional' fue bautizado por Pradier (2001) para representar aquel estado emocional provocado por dos factores, el impacto sensorial y la reflexión, que circula en dirección contraria a la catarsis. Un proceso auto experimental que surge tras la percepción artística y que está formado por el tránsito de un fenómeno emocional de gran impacto, para, posteriormente, provocar una sensación de vacío de contenido íntimo. El fenómeno conecta con la reflexión propia a través de la empatía sobre el impacto en otros (los intérpretes), interviniendo las emociones de dolor, miedo e incertidumbre, que se entremezclan consiguiendo un peculiar colapso sentimental, cercano al concepto de purga.

La catarsis ha sido analizada y explicada por muchos autores, en búsqueda de comprender cómo afectan las emociones a los actos humanos y su praxis social. Pradier define el término explicándolo del siguiente modo: "Término médico que asimila la identificación a un acto de evaluación y de descarga afectiva; no queda excluido que de ella resulte un 'lavado' y una purificación por regenerescencia del yo percibiente. Esta purga ha sido asimilada a la iden- 
tificación y al placer estético, está vinculada al trabajo del imaginario y de la producción de la ilusión escénica" $(1997,65)$.

Con esta explicación vemos cómo para Pavis es esencial el proceso de evaluación personal del espectador, transitado por medio de la empatía. Además, concreta en el diálogo entre obra y espectador, cuya conexión y entendimiento es de gran importancia, utilizando el impacto emocional y la percepción sensorial del acto performativo, acompañado de la impresión visual, característica propia de las artes escénicas. Por otro lado, es significativo el uso del concepto de 'purga' aplicado como proceso de auto-limpieza y regeneración que provoca el mismo impacto emocional.

Continuando con la definición de Pavis, encontramos que "el psicoanálisis la interpreta -la catarsis- como placer obtenido de las emociones propias ante el espectáculo de las emociones del otro, y placer de volver a sentir una parte del propio yo reprimido que toma la forma tranquilizadora del yo del otro" ([1983] $1998,65)$. En esta ocasión, el autor señala al carácter reprimido del espectador, aquello que guardamos bajo la alfombra, en la oscuridad, evitando que vea la luz social. Especialmente ese carácter es el que habla de nosotros mismos, el verdadero Yo, y, según Pradier (2001), son los elementos con los que debe de conectar la obra: sus miedos, sus anhelos, sus deseos, su dolor o sus pasiones. De modo que, el fenómeno de 'la inauguración emocional' se ocuparía de sustituir la euforia provocada por la catarsis, incorporando estos miedos ocultos, que saldrían a la luz en forma de sensación de vacío. Estamos ante un proceso de psicoanálisis centrado en la extracción de 'lo íntimo', mediante la auto-observación y su reflexión, para posteriormente conseguir una verdadera autocrítica. Proceso donde intervienen emoción, empatía e imaginación, pues como afirma Pradier "sin imaginario no hay emoción, sin emoción no hay motivación, sin motivación no hay acción, sino apatía, falta de vitalidad y muerte" $(2001,9)$.

\section{DESARROLLO DE LA 'INGURGITACIÓN EMOCIONAL’ ENTRE LOS PROCESOS CREATIVOS}

La búsqueda de la 'ingurgitación emocional' en la danza comienza de manera inconsciente entre los coreógrafos expresionistas. Las obras emblemáticas: 
Hexentanz (1914) de Mary Wigman o La Mesa Verde (1932) de Kurt Jooss, son símbolos del contexto de entreguerras que se liberan del peso de la dramaturgia clásica y del corsé del vocabulario del ballet, ofreciendo libertad con la exposición de pensamientos desafiantes ante el sistema y mostrando las tinieblas que habitan dentro del alma y la psique de los autores. Wigman propone en su creación contrastes de energía con los que se pautan los movimientos, junto intensos cambios de dinámicas que abracan desde lo sutil a lo fragmentado. En la gestualidad facial habita gran histrionismo, acorde con la utilización de las extremidades superiores tensas y semiótica en las manos que llaman la atención por su tensión desmesurada, esta simbología crea alusiones a la inestabilidad emotiva, enfatizando la idea de inconformidad social y opresión política. Por su parte, Joos propone en su estructura de puzle un planteamiento más reivindicativo y crítica política. La magistralidad de la obra reside en conectar unas escenas cómicas y satíricas (que relajan al receptor), junto a otras escenas de intensidad emocional y tensión dramática (que por el contrario, lo alteran), consiguiendo despertar los sentidos y estimular las emociones junto a la reflexión. En su totalidad se motiva al espectador a realizar una lectura holística que abarca simbología, estados emocionales y empatía por la importancia del discurso social; provocando así un circuito emocional y psicológico, que concluye en una metaemoción de alto impacto. Una llagada a la 'ingurgitación emocional' desde la 'verdad' y 'libertad'.

Una paso más profundo hacia las emociones realizó el surrealismo con la presencia de Hélene Vanele en la escena, quien encarna en su obra la fantasía y lo antirracional surrealista, haciendo tangible el contenido inconsciente a través de piezas e imágenes enigmáticas, oníricas y confusas. Un momento estelar fue su participación en la Exposición Internacional de Surrealismo de 1938, con un performance llamado L'acte manqué (El acto abortado) donde interactuaba con las pinturas y las esculturas expuestas en las diferentes salas. Vestida por Dalí, con un vestido volátil blanco, la bailarina proyectaba una danza visceral, extravagante y alocada, con cierta esencia sonámbula y con ritmos disonantes y contradictorios. Se considera que esa actuación fue el primer ejemplo auténtico del surrealismo en el terreno de la danza (Lehmann $2016)^{7}$

La performace comenzaba con un juego de sorpresa para el público. Los espectadores se encontraban con la bailarina completamente desnuda y encadenada a unas camas, mientras intenta liberarse de las sábanas que cubren su cuerpo, dejando ver poco a poco su piel entre los espasmos de una crisis de histeria. Poco a poco, esa histeria se descontrola, lanzando las almohadas 
al aire que provocaban el vuelo de plumas y otros elementos oscuros que simbolizaban el vuelo de murciélagos, mientras gritaba asustada arrojándose hacia el público. La segunda parte de la actuación fue frenética y escandalosa; Vanel apareció de la nada, esta vez con el diseño de Dalí, golpeando las paredes y gritando, portando un gallo vivo entre los brazos que acompañaba con sus gritos a la bailarina. La tercera y última parte, fue la más sosegada de su actuación. Vanel aparece en una sala donde había una estufa encendida, se acerca a ella y realiza una especie de veneración al fuego, reviviendo un estado de éxtasis reflejado en sus movimientos: muecas exageradas, movimientos grotescos y sacudidas con el cuerpo (Lehmann 2016). El estilo coreológico de Vanel responde a las premisas estéticas del surrealismo y su pasión por la histeria, como representación de estados emocionales otorgados por la presión social y no como enfermedad mental. Un viaje emocional donde residía la 'ingurgitación emocional' como meta final.

Más tarde, Pina Bausch, continuará investigando intensamente sobre esta emoción, buscando acceder a la catarsis desde otro camino emocional, indagando en la exposición de la cruda verdad sobre la escena (Sánchez 1999) y escavando escénicamente en la exposición del psicoanálisis social (Pradier 2001). Café Müller (1978) se estrena en el Opernhaus Wuppertal, mostrando una coreografía que danza el diario íntimo y, quizás, psicoanalítico de sus personajes. En ella se muestran las relaciones de personajes que se encuentran, sin intención, en un café. La singularidad reside en el discurso que ofrece cada personaje, narrado de forma visceral, desnudo y desde una perspectiva emocional y psicológica. La obra ofrece un mundo lleno de conflictos, donde cada problema posee una referencia común, real y general, vinculada con lo social. El material coreográfico está compuesto en gran medida por el vocabulario no verbal (natural social) y de códigos semióticos de sentido referencial y condensación que facilitan el diálogo intérprete-espectador (objetivo), al igual que la lectura privada (subjetiva) que realiza el observador. El carácter magistral de la composición reside en conseguir conectar empáticamente al espectador con cada escena y cada personaje. Planteamiento que entrega al espectador una posición de psicólogo que habla con cada intérprete a la vez que hace suyo el problema, estableciendo un tránsito emocional por diferentes estados: soledad, dolor, tristeza, abandono, etc., un proceso concatenado de emociones, de carácter cíclico y agotador, que concluye en ese vacío íntimo propio de la ‘ingurgitación emocional' o como diría Pavis, en una (auto) purga. 


\section{CONCLUIONES}

Con estas prácticas escénicas, se observa una aplicación de las emociones en la coreografía de manera natural y respetando su episteme comunicadora. La naturaleza propia del cuerpo humano recrea en su fisionomía movimientos, posiciones y locomociones extraídas de la experimentación de los fenómenos emocionales, compuestos por acciones musculares complejas, con ritmos diferentes y con intensidades diferentes de 'esfuerzo', cuyo efecto proporciona innumerables cualidades de movimiento.

Con estas propuestas de obras modernistas de danza se redirige, en la práctica, el rumbo coreológico, atendiendo a la emoción, que es insertada de forma pura en los procesos creativos y extrayendo la fisionomía natural del fenómeno emocional como material coreográfico puro.

El planteamiento del 'giro corporal' realizado por las vanguardias europeas evoca una necesidad de renovación de la catarsis más vinculada a la realidad social, un contexto marcado por la devastación de dos guerras que cambian la praxis del mundo, la forma de vivir y los deseos futuros. Los creadores muestran sobre las tablas un escenario donde el dolor, el miedo y las tinieblas no se ocultan, y que, por el contrario, son importantes para comprender quiénes somos. Esta 'verdad' y 'libertad' ayuda a digerir las nuevas obras de danza, que ya no hablan de ideales, sino de realidades, planteando la 'ingurgitación emocional' como una metaemoción como finalidad artística.

Desde la distancia, podemos analizar con detalle cada momento visceral que pautó la creatividad de nuestros antecesores, para así atender con precisión la actualidad de la danza, donde la 'ingurgitación emocional' se puede presentar como objetivo del proceso creativo y, quizás, como símbolo de la obra contemporánea.

Referencias bibliográficas

Albizu Larruskain, Ibis. 2015. 'El surgimiento del racionalismo cartesiano en la teoría de la danza barroca: De Arbeau a Feuillet pasando por la 'Académie Royale de Danse' de Luis XIV'. Tesis Univ. Complutense

Andrew, Nell. 2014. 'Dada Dance: Sophie Taeuber's visceral abstraction'. Art Journal 73(1): 12-29. doi:10.1080/00043249.2014.918806 
Bovin, Mette. 1974. 'Ethnic performance in rural niger: An aspect of ethnic boundary maintenance'. Folk 16-17: 459-74

Bürger, Peter. (1974) 1997. Teoría de la vanguardia. Traducción de Jorge García; prólogo de Helio Piñón. Barcelona: Península

Goldberg, RoseLee. (1988) 1996. Performance art: Desde el Futurismo hasta el presente. Traducción, Hugo Mariani. Barcelona: Destino

Gómez García, Manuel. 2001. 'Escritura teatral: De las vanguardias al futuro'. Monteagvdo 6: 53-6; https://revistas.um.es/monteagudo/article/view/77721

Grumann Sölter, Andrés. 2008. 'Estética de la 'danzalidad' o el giro corporalidad de la 'teatralidad'. Aisthesis 43: 50-70. http://www.redalyc.org/articulo.oa?id=163219835004

Laban, Rudolf Von. (1950) 1989. El dominio del movimiento. Ed. corr. y ampl. por Lisa Ullmann; traducción, Jorge Bosso Cuello. Madrid: Fundamentos

Lehmann, Maria-Rosa. 2016. 'L'acte manqué (1938): Surrealism between insanity and performance art; Staging the human body under the strain of hysteria'. Acta lassyensia Comparationis 17(1): 47. https://www.ceeol.com/search/article-detail?id=712030

Markessinis, Artemis. 1995. Historia de la danza desde sus orígenes. Prólogo de Rosella Hightower. Madrid: Librerías Deportivas Esteban Sanz

Mera Felipe, Guadalupe. 2011. 'Los ilustrados y la danza a principios del siglo XIX: Polémicas sobre la construcción de una identidad nacional frente al modelo francés'. En Coreografiar la historia europea: Cuerpo, política y género en la danza, Beatriz Martínez del Fresno, ed., 173-99. Oviedo: Universidad de Oviedo

Pavis, Patrice. (1983) 1998. Diccionario del teatro. Prefacio de Anne Ubersfeld; traducción de Jaume Melendres. Barcelona: Paidós

Pradier, Jean-Marie. 1997. 'Etnoescenología: La profundidad de las emergencias'. Cuadernos de Teatro (Buenos Aires) 11: 49-50

Pradier, Jean-Marie. 2001. 'Artes de la vida y ciencias de lo vivo'. Conjunto: Revista de Teatro Latinoamericano 123: 14-27. https://es.scribd.com/document/49397049/Pradier-2-artesde-la-vida-y-ciencias-de-lo-vivo

Sánchez Bueno, Soledad. 2001. Reseña de La disciplina coreologica in Europa: Problemi e prospecttive de Cecilia Nocili \& Alessandro Pontremoli, eds. Trans: Revista Transcultural de Música 15: 1-8

Sánchez Martínez, José Antonio, ed. 1999. La escena moderna: Manifiestos y textos sobre teatro de la época de vanguardias. Madrid: Akal

Sapiain, Carolina. 2015. 'El objeto de la etnoescenología frente al predominio del modelo escénico occidental'. El Sótano 5: 33-6. https://www.yumpu.com/es/document/read/15813299/ el-objeto-de-investigacion-de-la-etnoescenologia-frente-el-sotano/5

Schlemmer, Oskar. (1925) 1961. 'Man and art figure'. En The theatre of the Bauhaus, Oskar Schlemmer, Laszlo Moholy-Nagy \& Farkas Molnar, edited by Walter Gropius \& Arthur S. Wensinger; translated by Arthur S. Wensinger, 17-48. Middletown CT: Wesleyan University

Taylor, Diana. 2011. 'Usted está aquí: El ADN del performance'. En Estudios avanzados de performance, Diana Taylor \& Marcela Fuentes, eds., 401-30. Ciudad de México: Fondo de Cultura Económica

Turner, Victor Witter. 1982. From ritual to theatre-the human seriusness of play. New York: PAJ 
Viana Cisneros, Luis Felipe. 2009. 'Coreología de la urbanidad'. Trabajo de grado-maestría, Univ. Nacional de Colombia. https://repositorio.unal.edu.co/handle/unal/2397

Walker, Kathrine Sorley. (1972) 1979. La danza y sus creadores: Coreografos en acción. Traducido del inglés por Gerardo V. Huseby. Buenos Aires: Victor Leru

\section{Notas}

${ }^{1}$ Antonio Sánchez (1999) define el s. XX y las propuestas vanguardistas como 'dramaturgias de la imagen', defendiendo que la 'argumentación' en la obra escénica desaparece sintetizándose en 'concepto', que a su vez se inserta simbólicamente en la imagen escénica, mediante la abstracción. Para realizar este fenómeno se introduce a grandes pintores, diseñadores y arquitectos a colaborar en el proceso creativo, trabajando en igualdad de importancia junto al director de la obra. Paralelamente a esta valoración de la imagen, RoseLee Goldberg (1996) y Diana Taylor (2011) hablan sobre el valor revolucionario de la performance como estilo de obra construida para activar al espectador, hacerlo partícipe de la misma y ofrecerle espacios de libre lectura.

${ }^{2}$ Como explica Peter Bürger (1974), los artistas de vanguardias buscaron, a través de otras vías comunicativas y con nuevas ideas e ideales, ofrecer una ayuda a praxis vital, entendiendo el arte como vida y ofreciendo con las obras una manera de ayudar a tener alternativa social diferente a la común, que mejorara la empatía, la positividad y las relaciones entre el agente y los demás elementos sociales (economía, educación, política, ética, ideología, etc.).

${ }^{3}$ La danza dadaísta, futurista y surrealista, exaltaba la gestualidad como brote del alma y los sentimientos. La concepción del espacio junto al cuerpo del intérprete obsesionó a teóricos y diseñadores (de escenografía y coreografía). Las teorías de Laban ([1950]1989) modificaron el concepto de danza por cinética y espacio, como en el trabajo con la bailarina Dadá Sophie Taeuber en Gesang der Flugfishe und Seepferdchen (1917), cuyas enseñanzas ayudarían a adaptar los movimientos a su traje dadaísta, que encerraba su movilidad con límites muy definidos, "resistiendo los controles institucionales, morales y culturales del lenguaje escrito y hablado, el género, los gestos y el placer, las mismas ideologías que Dadá implicaba en llevar un mundo pasivo a la guerra total" (Andrew 2014, 18). Con el mismo planteamiento, desde la Bauhaus, Oskar Schlemmer (1925) propone su 'Tänzermensch' ('Hombre como bailarín') partiendo de sus dos teorías: las 'leyes del espacio cúbico' y las 'leyes del ser orgánico'.

${ }^{4}$ Una clara ruptura de la estética tradicional fueron los diseños futuristas de Giacomo Balla para sus obras Macchina tipográfica (1914) y Fuegos artificiales (1917). Más tarde, el dadaísmo se encargaría de geometrizar los vestuarios de Sophie Tacuber, para Gesang der Flugfishe und Seepferdchen (1917). En este mismo año Picasso traza los diseños de Parade (1917), ballet creado por los ballets de Diaguilev bajo los parámetros surrealistas. Con estas innovaciones, la coreografía abre fronteras estéticas que ayudan al mensaje y a su comprensión, facilitando la exposición psicológica y emocional que puede contener la obra.

${ }^{5}$ Las nuevas perspectivas etnoescenológicas para afrontar la danza, proporcionan al creador las herramientas para poder expresar su mundo ideológico, emocional, onírico, desde una libertad completamente subjetiva y analógica. Estos procedimientos que unen escena y sociología también son denominados como 'ethnic performances' por Bovin (1974) o en términos de Turner (1982) el 'social drama'. Sobre las relaciones entre el ritual social y el teatro, ambos autores conectan las esferas espirituales y corporales, manifestadas en 
los acontecimientos escénicos sociales, entendidos como 'ritual social', con las praxis del teatro (en intención y objetivos). Estas vinculaciones fomentan la concepción espistémica de la etnoescenología en lo teatral. La idea que plantea esta investigación doctoral apoya las bases ideológicas de una obra escénica visceral y verdadera entorno al agente social, que desarrolle toda una cristalización del 'hombre', abarcando su posición política, social, cultural y emocional (Bovin 1974; Turner 1982).

${ }^{6}$ Luis Felipe Viana (2009) analiza cómo en la cultura el carácter evolutivo puede estar formado por una respuesta en disputa con el estilo predecesor, relacionadas con el devenir del agente social transitando su sociedad que se sitúa en una plataforma conflictiva o de cambios. De este modo, se fractura la línea de trabajo, emergiendo una propuesta escénica contraria como oposición a la anterior.

${ }^{7}$ María Rosa Lehmann $(2016,47)$ narra sobre la actuación de Vanel: "La inauguración de la exposición contó con la medianoche de una bailarina semidesnuda, Hélène Vanel, que, agitándose, retorciéndose y gritando, corrió hacia el medio de la multitud para dar una impresión dramática, y demasiado real, de un ataque histérico. Sus movimientos aparentemente caóticos han sido descartados por la mayoría de los estudiosos como una mera manifestación de frustración sexual".

(Artículo recibido: 19-02-21; aceptado: 26-05-21) 